\title{
Ofelia Uribe de Acosta: Crítica a la educación colombiana
}

\author{
Ofelia Uribe de Acosta: Criticism of colombian education
}

\author{
Ofelia Uribe de Acosta: Crítica à educação colombiana
}

\author{
Wilma Nury Blanco Ruiz ${ }^{1}$ \\ Universidad Pedagógica y Tecnológica de Colombia - Colombia \\ Grupo de Investigación GIEPEG en Alianza con HISULA \\ vilmanury@gmail.com
}

Recepción: 15/09/2014

Evaluación: 16/10/2014

Aceptación: 24/11/2014

Artículo de reflexión

\section{RESUMEN}

En junio de 1963 la feminista colombiana Ofelia Uribe de Acosta publicó el libro Una Voz Insurgente, en el que dio testimonio de la realidad social de Colombia, y especialmente de las mujeres, en el período comprendido entre los años 1930 y 1963; en particular, en el capítulo dieciocho, la autora expuso sus ideas sobre la educación colombiana y manifestó que ésta no había avanzado desde el siglo XIX debido al manejo que la élite gobernante le daba al país. El espíritu rebelde de Ofelia Uribe quedó condensado a lo largo del libro frente al paterfamilias que, según ella, perdió la calidad moral de rector de la sociedad y no respondía a los cambios sociales, económicos y políticos que se generaban en todo el territorio nacional.

El artículo se desarrolla a través de fuentes primarias; se centra en la descripción de la vida de Ofelia Uribe de Acosta, su pensamiento crítico frente a la educación colombiana, a luz de los acontecimientos del momento, y una reflexión final que recoge fallas de la educación, abordadas por Ofelia Uribe de Acosta y que se relacionan con la educación del siglo XXI.

Palabras clave: Revista Historia de la Educación Latinoamericana, Ofelia Uribe

\footnotetext{
1 Socióloga Magíster en Desarrollo Rural, profesora de la Licenciatura en Ciencias Sociales de La Universidad Pedagógica y Tecnológica de Colombia, UPTC-Tunja, integrante del grupo de Investigación GIEPEG en Alianza con HISULA, este articulo se interrelaciona con el proyecto "La Universidad en la capacitación de maestras rurales SGI 1034" y "Las educadoras en las Escuelas Normales en Colombia SGI 1293" desarrollado por el grupo HISULA - UPTC.
} 
de Acosta, Feminismo, Politica, Educación, Colombia, Mujeres.

\section{ABSTRACT}

In June of 1963 the Colombian feminist Ofelia Uribe de Acosta published the book Una voz insurgente (an insurgent voice), where this book gave testimony to the social reality of Colombia and especially the women one between 1930 and 1963. Particularly, in the eighteenth chapter, the author presented her ideas about the Colombian education and she said that this had not progressed since the 19th century due to the management that the elite government gave the country. The rebellious spirit of Ofelia Uribe remained throughout the book against the paterfamilias that, according to her, it lost the moral quality of society rector and it did not respond to social, economic and political changes that appeared throughout the national territory.

The article develops through primary sources. It focuses in the description of the life of Ofelia Uribe de Acosta, her critical thinking in front of the education in Colombia, in the light of the events of the time, and, a final reflection that collects the weaknesses of education related to education in the twenty-first century addressed by Ofelia Uribe de Acosta.

Key words: History of Latin American Education Journal, Ofelia Uribe de Acosta, Feminism, Politics, Education, Colombia, Women.

\section{RESUMO}

Em junho de 1963, a feminista colombiana Ofelia Uribe de Acosta publicou o livro Uma voz Insurgente, em que deu testemunho da realidade social da Colômbia e especialmente das mulheres, no período compreendido entre os anos 1930 e 1963; em particular, no capítulo dezoito, a autora expôs suas ideias sobre a educação colombiana e manifestou que esta não havia avançado desde o século XIX devido ao tratamento que a elite governante dava ao país. O espírito rebelde de Ofelia Uribe acabou condensado ao largo do livro frente ao paterfamilias que, segundo ela, perdeu a qualidade moral de reitor da sociedade e não respondia às mudanças sociais, econômicas e políticas que eram geradas em todo o território nacional.

O artigo parte de fontes primárias; é centrado na descrição da vida de Ofelia Uribe de Acosta, seu pensamento crítico frente à educação colombiana, à luz dos acontecimentos do momento, e uma reflexão final, que recorre a falas sobre a educação abordadas por Ofelia Uribe de Acosta, que se relacionam com a educação do século XXI.

Palavras-chave: Revista História da Educação Latino-americana, Ofelia Uribe de Acosta, feminismo, política, educação, Colômbia, mulheres. 


\section{INTRODUCCIÓN}

Cuando me propuse escribir sobre Ofelia Uribe de Acosta, pensé que no tenía las fuentes suficientes para hacer un artículo y cumplir con los requerimientos establecidos para tal fin en el ámbito académico. No obstante, consideré necesario rescatar y valorar la voz de las mujeres que, como Ofelia Uribe de Acosta, se atrevieron a abrir los debates sobre la situación social y política del género femenino desde los años treinta del siglo XX en Colombia y con el propósito de continuar recogiendo elementos específicos que apoyen la construcción de los entramados sociales y políticos que fueron parte del contexto histórico de su tiempo. Asimismo, cobra importancia el hecho de que Ofelia Uribe de Acosta trasciende en sus reflexiones al análisis de lo social, económico y político de la Colombia de ese momento.

El artículo gira en torno a las siguientes preguntas: ¿Cómo fue la vida de Ofelia Uribe de Acosta y cuáles fueron sus acciones políticas que la destacaron como una de las feministas sobresalientes entre los años treinta y sesenta del siglo XX? ¿Cómo trató el tema de la educación en Colombia en el libro Una Voz Insurgente? ¿Cuáles de los análisis y propuestas sobre la educación colombiana, hechos por Ofelia Uribe de Acosta, se mantienen en la actualidad?

En consecuencia, el artículo tiene como objetivo rescatar el pensamiento de Ofelia Uribe de Acosta, con el fin de relacionar su empoderamiento temprano y sus consideraciones sobre la política nacional y, particularmente, sobre la educación en un contexto en el que la autonomía social, política y económica de las mujeres no era tenida en cuenta pues se connaturalizaba su subordinación en todos los órdenes sociales.

Las fuentes para la elaboración de este artículo se basaron en el libro Una Voz Insurgente, publicado por la Editorial Guadalupe en 1963; en la entrevista que Ofelia Uribe de Acosta le concedió a la poetisa Anabel Torres en 1986, que aparece en la revista Voces Insurgentes de la Universidad Central de Bogotá; en el documental emitido por la televisión pública de Colombia, en 2004, en el programa Contravía, con ocasión de la conmemoración de los 50 años del voto femenino en Colombia, con entrevista grabada antes de su muerte; y en un documento de Magdala Velásquez, publicado en la revista Credencial Historia, en 1995, en el que aborda brevemente la vida de Ofelia Uribe de Acosta. De igual manera, se tienen en cuenta otras fuentes secundarias que permiten sustentar con datos estadísticos algunos temas.

El momento histórico en el que Ofelia Uribe de Acosta se pronunció se contextualiza en un país en el que, conjuntamente con el crecimiento vertiginoso 
de la población, operaba el proceso de industrialización. Para este momento Colombia, según el censo nacional de 1964, contaba aproximadamente con 17.484.508 habitantes, con predominancia de la población en las áreas urbanas. El analfabetismo en personas mayores de quince años era el doble en el ámbito rural, y las más afectadas eran las mujeres ${ }^{2}$. Asimismo, el país experimentaba transformaciones que se expresaron en la emergencia de grupos sociales como agremiaciones y sindicatos que aspiraban a movilizar a la opinión pública con inquietudes económicas y sociales que posibilitarían el equilibrio nacional. De otro lado, es importante señalar que la autora de Una Voz Insurgente escribió y publicó el libro en un momento en que Colombia "se recuperaba" de lo que se denominó la "época de la Violencia", desatada por el asesinato del político liberal Jorge Eliécer Gaitán en 1948, a través de lo que la dirigencia de los dos partidos políticos hegemónicos — liberal y conservador- llamaron el Frente Nacional, que consistió en la alternancia consensuada para gobernar por períodos cada cuatro años durante dieciséis años, lo cual incidió en el estancamiento de la cultura política de la nación.

El artículo desarrolla tres apartados: en el primero se hace una síntesis biográfica de Ofelia Uribe de Acosta; en el segundo se destacan algunas consideraciones generales mencionadas en el libro sobre la educación colombiana, e incluye las ocho fallas identificadas por la autora; y en el tercero se concluye con un análisis comparado en el tiempo, que demuestra que la mayoría de las percepciones e interpretaciones de Ofelia Uribe de Acosta mantienen vigencia actual en Colombia.

\section{Las traviesas muñecas de salón}

Ofelia Uribe de Acosta fue una de las pioneras de la reivindicación de los derechos de las mujeres y del periodismo independiente en Colombia. Su vida transcurrió a lo largo del siglo XX —nació en 1900 en Oiba, Santander, al oriente de Colombia y murió en Bogotá en 1988-; fue la mayor y única mujer de los cinco hijos de un matrimonio con raigambre liberal; a los 86 años recordaba, en entrevista con Anabel Torres, que su infancia transcurrió compartiendo con sus hermanos juegos que no eran propios para las niñas y que ya ella comparaba esas diferencias permitidas o negadas para unos y otras como practicar tiro al blanco, corretear, brincar o leer libros que estaban incluidos en el Índice de Libros Prohibidos publicado por la Iglesia católica, como los del escritor colombiano Vargas Vila. Las mujeres, en particular, solamente podían leer libros sobre la vida de los santos y de cocina. Recuerda también que, desde su infancia, el medio la

2 Asociación Colombiana para el Estudio de la Población -ACEP-. La población de Colombia. COMMITER, 1974. http://www. cicred.org/Eng/Publications/pdf/c-c9.pdf. (19/06/2014). 
empujaba a cultivar las tres virtudes que ella consideraba negativas para la mujer: callar, ignorar y obedecer.

Las mujeres no podían matricularse en la universidad, pues estaban destinadas al matrimonio, al convento o al magisterio; por ello Ofelia Uribe logró convencer a su padre de que le permitiera estudiar en la Escuela Normal, que era la única educación al alcance de las mujeres y, además, el único recurso para estudiar más allá de la primaria, se tuviese o no vocación para ser maestra; en consecuencia se graduó como normalista a los 17 años y ejerció durante un año en una escuela de primaria. Dado que los primeros 30 años del siglo XX fueron gobernados por el Partido Conservador, no logró el apoyo para un colegio que ella, junto con su madre, pretendían establecer en el municipio del Socorro, debido a la adscripción familiar al Partido Liberal.

A los 26 años se casó en el municipio de Miraflores, Boyacá, con Guillermo Acosta, sobrino de quien fuera presidente liberal en el siglo XIX: el general Santos Acosta. Este parentesco le posibilitó moverse en un ámbito social que favorecía las acciones feministas que realizaba con otras activistas de la época. Una de las anécdotas que narró en entrevista para la televisión es cómo su novio, quince días antes del matrimonio, le advirtió que de la puerta de la calle para fuera él sería amo de todas sus actuaciones y que de la puerta para dentro ella sería reina del hogar y dueña de todo, a lo cual ella le manifestó que en esas condiciones no se casaría porque él tendría toda la libertad y ella, ninguna, pues ella quedaría enclaustrada y él, libre ; finalmente acordaron hacer un convenio entre los dos, que después se llamaría capitulaciones matrimoniales y que incluiría las mismas libertades, los mismos derechos y las mismas obligaciones para los dos.

Dada su profesión de abogado, Guillermo Acosta fue nombrado juez en el municipio de San Gil, Santander, y ella decidió trabajar con él hombro a hombro durante casi cinco años. Así aprendió a investigar, hizo de escribiente y citó testigos, entre otras cosas. De acuerdo con la historiadora Magdala Velásquez, "Con esta experiencia, [Ofelia Uribe] adquirió conocimientos jurídicos, conceptos y elementos para comprender la función del Estado y de la política"4.

En 1930 se inició el gobierno del liberal Enrique Olaya Herrera, luego de más de tres décadas de hegemonía conservadora en la dirección del Estado. Aunque las mujeres no tenían derecho a sufragar, salieron a las plazas públicas a apoyar al candidato que se hizo presidente, pues se buscaba un programa de gobierno

\footnotetext{
3 Programa Contravía TV. Capítulo 53. Entrevista realizada a Ofelia Uribe de Acosta, en el documental emitido el 25/08/2004 con motivo de la conmemoración de los 50 años del voto femenino.

4 Magdala Velásquez Toro, Ofelia Uribe de Acosta. Revista Credencial Historia No.68.(2014) http://www.banrepcultural.org/blaavirtual/revistas/credencial/agosto95/agosto4.htm (10/04/2014).
} 
que modernizara a Colombia en consonancia con el proceso de industrialización que se venía dando en el país. Era un momento en el que se requería mano de obra libre dispuesta a trabajar en las fábricas y el establecimiento de un sistema político laico que potencializara la capacidad de educación de la población. En este contexto, se empezó a originar el movimiento feminista sufragista, del cual hizo parte activa Ofelia Uribe de Acosta.

El gobernador liberal del departamento de Boyacá la delegó al IV Congreso Internacional Femenino, realizado en Bogotá en 1930, en el cual Ofelia presentó una ponencia sobre los derechos civiles de las mujeres casadas, que proponía el manejo de los bienes propios y la independencia económica. La ponencia recogía el sentir de las mujeres que necesitaban y querían trabajar y de las mujeres de las clases altas, quienes sentían malestar porque sus herencias eran dilapidadas por sus maridos a su antojo. Su intervención en este congreso se convirtió en un aporte fundamental para que en 1932 la Ley 28 otorgara a las mujeres casadas derechos sobre sus propios bienes.

Magdala Velásquez encuentra en el periódico El Tiempo del 1 de enero de 1931 el pronunciamiento de Ofelia Uribe de Acosta: “...El feminismo acaba de nacer en Colombia como producto natural de evolución, pero todavía son muchas las mujeres que retroceden espantadas ante la repentina aparición de esa palabra que viene a turbar su mísera condición de siervas humilladas, pero insensiblemente connaturalizadas con su papel de víctimas" ${ }^{\prime 5}$.

Inmediatamente Ofelia Uribe de Acosta, con Beatriz de Burgos, intervinieron directamente ante el presidente Olaya Herrera por lo que en el momento se consideraba el derecho a la cultura para las mujeres, que se materializaría con la expedición en 1933 del Decreto 1972, que abrió las puertas de la universidad a la mujer colombiana. Estos dos triunfos en el gobierno de Olaya Herrera fueron producto de la primera organización feminista en Colombia y se convirtieron en logros significativos, al punto que la mayoría de las mujeres que hacían parte de esta organización consideraron que fue en este gobierno cuando se empezó a realizar la liberación de las últimas personas esclavizadas en Colombia: las mujeres.

En el gobierno siguiente, del también liberal Alfonso López Pumarejo, las feministas colombianas alcanzaron en una reforma constitucional el derecho a desempeñarse en empleos públicos. Se designó a la primera mujer para uno de los juzgados de Bogotá, lo cual produjo conmoción y demandas al Estado. Este hecho llevó a Ofelia Uribe de Acosta a recorrer el país, dictando conferencias

$5 \quad$ Ibídem (documento sin paginar). 
donde le fuera permitido hablar, pues comprendió muy bien que, sin la agitación necesaria, las leyes y decretos logrados para favorecer a las mujeres se podían convertir en letra muerta. La oposición incluso estaba en las mismas mujeres y en muchos sectores políticos.

Es así como en 1937 logró un espacio en Radio Boyacá, en la ciudad de Tunja, en donde se empezó a transmitir el programa La horafeminista, un espacio de una hora varios días a la semana. El interés y el impacto que tuvo el programa quisieron ser contrarrestados con otro programa dirigido por señoras "prestantes" de la ciudad, con duración de una hora también, que se llamó La hora azul y cuyo propósito se centró en alabar las virtudes y recatos femeninos. No obstante, la emisión de La hora feminista tuvo ecos en Bogotá, donde se fundó la Unión Femenina de Colombia; esta organización realizó un memorial, encabezado por la bogotana Lucía Rubio de Laverde, dirigido al gobierno y que reclamaba el derecho al sufragio, y desde Tunja se reunieron más de 500 firmas $^{6}$. Estas acciones llevaron a que la prensa nacional incrementara las agresiones contra las mujeres que decidieron exigir estos derechos. Si en un comienzo, señaló Ofelia: "A los hombres les había parecido una 'gracia' nuestra batalla, nos decían 'traviesas muñecas de salón', en actitud paternalista y displicente. Ahora comienzan a sentirse amenazados por el ímpetu que iba cogiendo nuestro movimiento"7.

Ofelia Uribe comentaba: "La prensa decía que el voto de las mujeres iba a corromper a las propias mujeres, es decir que lo femenino tenía por naturaleza el lugar del hogar para expresarse y que si salía de ese lugar iba a perder su feminidad. El perfume de la mujer era un perfume quintaesenciado que residía en la cabeza de la mujer y al menor contacto con las disciplinas de la inteligencia se evaporaba el perfume y quedaban convertidas en marimachos horrendos, no se podía hablar de derechos porque se les evaporaba el perfume entonces, las mujeres huyeron espantadas ninguna quería hablar de derechos porque perdían el perfumito" ${ }^{\prime 8}$.

Como respuesta a los ataques de los periódicos de mayor circulación en el país y al hecho de que las feministas no tenían un medio para expresar sus pensamientos y presentar sus proyectos, Ofelia Uribe, que con el programa de radio había logrado constituir un equipo de trabajo, lanzó la revista Agitación Femenina, cuyo primer número apareció en Tunja en 1944. "Nosotras queríamos una voz para nuestros reclamos y para llamarnos las unas a las otras", señaló Ofelia. La revista estuvo en circulación hasta octubre de 1946.

\footnotetext{
6 Anabel Torres. “Una Voz Insurgente. Entrevista con Ofelia Uribe de Acosta”, Revista Voces Insurgentes, Universidad Central (1986): 32,33

7 Ibídem, 33.

8 Programa Contravía TV, op. cit.
} 
Magdala Velázquez destaca un artículo de primera página de Agitación Femenina, titulado "Curiosa paradoja", en el cual Ofelia Uribe de Acosta afirmaba: "Entendemos que la génesis del liberalismo fue la lucha por la conquista de los derechos individuales y de las libertades públicas...Por eso no entendemos que los mayoritarios del Congreso que se consideran los únicos depositarios y mantenedores de la tradición liberal, gastaron todas sus energías en impedir que la mujer colombiana obtuviera, con la totalidad de sus derechos ciudadanos, su significación individual y humana. ¿Es que el liberalismo no cuenta a las mujeres como personas?"'.

Su estadía en Tunja fortaleció su postura política frente a los derechos de las mujeres, por lo cual decidió asumir retos personales que confrontaran el establecimiento, como cuando se atrevió a matricular a una de sus hijas y a otra compañera suya, quienes aspiraban a estudiar en la universidad, en el Colegio de Boyacá, dado que en la ciudad no había liceo femenino para cursar el bachillerato clásico. Este hecho levantó protestas por doquier: los jerarcas de la Iglesia católica de Boyacá, a través del púlpito, expresaron su contrariedad por semejante desvergüenza; se reclamaba al Ministerio de Educación y al gobernador del departamento de Boyacá, exigiendo el retiro de las estudiantes del colegio. Ofelia Uribe de Acosta y su marido fueron citados a la capital de la República con el fin de convencerles de hacer el favor de no incomodar a la tradicional y conservadora sociedad tunjana, pero ellos se negaron rotundamente, aduciendo que se estaba en un gobierno liberal, un gobierno de avanzada y un gobierno de reformas que luchaba por el progreso; entonces el problema era del gobierno y era este el que debía solucionar la situación. La confrontación se resolvió a favor de la familia Uribe con la creación de una sección femenina para el Colegio Boyacá ${ }^{10}$.

Los antecedentes mencionados hasta aquí son relevantes en la consecución del voto para las mujeres en 1954 durante la dictadura de Rojas Pinilla, quien a través de un golpe militar llegó al poder en 1953 en un período en el que Colombia se desangró por la violencia política y que tuvo como detonante el asesinato del caudillo liberal Jorge Eliécer Gaitán el 9 de abril de 1948.

Durante la dictadura en el año 1955 se creó en Bogotá el periódico semanal Verdad, escrito y editado por mujeres, en la casa de Ofelia Uribe, con el fin de demandar la libre expresión para el periodismo; pero los ataques que recibió fueron más fuertes que los sufridos por la revista Agitación Femenina, por lo cual el último número de Verdad salió en agosto del mismo año, ante la advertencia

9 Velásquez Toro, op.cit. (Documento sin paginar).

10 Torres, op.cit., 36. 
de un amigo de Ofelia que trabajaba con el alto gobierno y quien le informó de la orden allanamiento a su casa ${ }^{11}$.

Después vino el Frente Nacional, pacto político a través del cual la dirigencia de los dos partidos políticos hegemónicos, liberal y conservador, se alternaron para gobernar el país por período de cuatro años durante dieciséis años, lo cual incidió en el estancamiento de la cultura política de la nación. Así lo afirmó Ofelia Uribe: "El Frente Nacional acabó completamente con la democracia. En primer lugar, porque convirtió al país en un botín para repartir [...] se acabaron los programas, se acabaron los ideales [...] y también porque la única condición sine qua non de la democracia es que exista oposición"12.

Durante el Frente Nacional, Ofelia Uribe de Acosta fue senadora suplente y fue silenciada; la clase dirigente le pasó la aplanadora por refutar a uno de los líderes del Partido Liberal, Alberto Lleras Camargo, quien fuera el primer presidente del Frente Nacional. Por su parte, el periódico El Espectador, después del plebiscito de $1957^{13}$, hizo apología al partido arrogándose el haber concedido el voto a las mujeres, desconociendo intencionalmente los avatares, luchas y ultrajes que habían recibido las "traviesas muñecas de salón", activistas colombianas durante tres décadas hasta la consecución del derecho al sufragio en 1954.

El pensamiento de Ofelia Uribe de Acosta quedó consignado en su libro Una Voz Insurgente, publicado en 1963 por la editorial colombiana Guadalupe, en el cual narró directamente sus experiencias y las de otras mujeres que consolidaron la primera organización feminista en Colombia, así como sus cuestionamientos críticos a la dirigencia política del país frente a la mecánica electoral, los partidos políticos y el problema de la violencia, la justicia y la educación en Colombia, entre otros aspectos.

\section{La mezquina nómina de intelectuales aptos para las tareas del gobierno}

A lo largo de su libro, Una Voz Insurgente, Ofelia Uribe de Acosta hace referencia constante al tema de la educación; en el apartado en el que abordó las ideas de feminismo y feminidad, invitó a las mujeres que se dedicaban al profesorado, y especialmente a las que tenían a su cargo la cátedra de antropología, a que se preocuparan por transmitir a sus estudiantes los orígenes de la civilización humana, pues con esto se forjarían las primeras luces en las mentes de las mujeres en el futuro ${ }^{14}$.

\footnotetext{
11 Ibídem, 38.

12 Ibídem, 39.

13 En el plebiscito de 1957 las mujeres votaron por primera vez en Colombia

14 Ofelia Uribe de Acosta,Una Voz Insurgente (Bogotá: Editorial Guadalupe, 1963), 48. 
Teniendo en cuenta los cambios socio-económicos que se daban aceleradamente durante lo que iba corrido del siglo XX, Ofelia Uribe de Acosta, desde su postura política, que ella definía como liberal de izquierda, insistía en la necesidad de un nuevo tipo de educación para la infancia y en una reeducación para adultos, que se lograría mediante una acción educativa permanente de líderes capaces de entender las nuevas pautas y dando estas a conocer al conjunto de la sociedad a través de pacientes labores de convencimiento.

Asimismo, planteaba la urgencia de la educación política:

“...si en todas las escuelas, colegios y universidades del territorio colombiano se prospectara de inmediato un moderno curso de educación política y de moral ciudadana, tendiente a despertar el espíritu de solidaridad humana y la necesidad de subordinar los intereses particulares al bien general, se daría el primer paso para el desarraigo del grosero egoísmo, que es fuente de todas las calamidades que nos azotan"15.

En el capítulo XVIII, dedicado específicamente a la educación, la autora planteaba que para que la economía, la justicia y la salud avanzaran era fundamental que se cimentaran en la educación, pues ésta se constituía en la arquitectura de los pueblos. Tanto las élites como las masas debían tener acceso a la educación pues las primeras elaborarían los planes y señalarían los derroteros y las segundas habrían de entenderlos, aceptarlos y colaborar inteligentemente a su interpretación ${ }^{16}$.

De otro lado, señalaba que el retroceso permanente en todos los órdenes de la actividad ciudadana se debía al inmovilismo de la educación en Colombia pues, después de sesenta años de corrido del siglo $X X$, se educaba con los mismos principios de 1800, cuando las relaciones sociales se conducían de acuerdo con los principios patriarcales, que establecían venerar y obedecer a quien se reconocía como ungido de extraordinaria y superior sabiduría.

Advertía Ofelia Uribe de Acosta que la élite se estancaba en sus privilegios e ignoraba con soberbia que el país había cambiado. El vertiginoso aumento de la población era evidente, y no se podía desconocer que la industrialización se posicionaba aceleradamente en Colombia y que, por el contrario, la clase dirigente se justificaba a través de expresiones como: "Este es un país ingobernable" y "La mezquina nómina de intelectuales aptos para las tareas del gobierno", que no eran más que excusas para explicar que la herencia era el único origen del talento para gobernar; de esta manera se ponían restricciones para aquellas

15 Ibídem, 116.

16 Ibídem, 349. 
clases o grupos sociales que, como las mujeres, fueron puestos en la condición de incapaces desde remotos tiempos ${ }^{17}$.

La sociedad colombiana requería de un rumbo más dinámico, para lo cual era necesario modificar el sistema educativo por uno que estuviese más acorde con los nuevos tiempos. La nueva sociedad industrializada se empezaba a caracterizar por la organización de gremios en defensa de sus intereses (sindicatos y asociaciones, entre otros) en defensa de los intereses de cada sector, pues se había comprendido que las acciones individuales por sí solas no tenían resonancia ante los gobernantes, mientras que las fuerzas organizadas podrían tener interlocución con el Estado.

Para Ofelia Uribe de Acosta, algunos gobernantes mantenían concepciones de la vida y del mundo que no correspondían con las realidades de su tiempo, rechazaban las demandas de los gremios y conculcaban sus derechos, y afirmaba: "nuestras élites dirigentes son, en la mayoría de los casos 'incapacidades preparadas' "18, por lo que necesitaban de una educación que les proporcionara elementos que les permitiera entender y aceptar que su función no consistía en gobernar rigurosamente de acuerdo con sus convicciones e intereses, sino que debía estar acorde con una administración que razonara sobre las necesidades e inquietudes de los gobernados. Por lo tanto, era fundamental transformar el sistema educativo, que debía contemplar dos fases: educación primaria y secundaria en lo general y reeducación para adultos.

La primera fase debería ir más allá de nociones librescas; estaría centrada en transmitir a la niñez hija de campesinos y trabajadores una conciencia plena de sus responsabilidades como ciudadanos útiles del país. Se debía circunscribir a sus entornos, ya fuera por cooperativas escolares, agrupaciones agrícolas o industriales, para que desde la infancia se asimilara y comprendiera que la solidaridad humana era fundamental para el bienestar y el progreso, pues la experiencia comunitaria conducía a pensar que los grupos organizados eran una fuerza constructiva. Este tipo de educación formaría para la integración social; además, era indispensable para resquebrajar ese arquetipo "de núcleo social estructurado sobre la autoridad del 'patersfamila', que ha perdido su calidad moral de rector" ${ }^{\prime 19}$.

Ofelia Uribe de Acosta sostenía que un hogar presidido por un padre irresponsable y bebedor que concebía su autoridad a través de la fuerza, con garrotazos y a fuete, se constituía en el ambiente en el cual la niñez abría los

\footnotetext{
17 Ibídem, 351.

18 Ibídem, 351

19 Ibídem, 354
} 
ojos a una vida en permanente conflicto. A su vez, las madres sometidas a estos abusivos métodos acudían a la mentira para esquivar las brutales imposiciones del "jefe de hogar", lo que terminaba convirtiéndose en una escuela inadecuada para los hijos. Al respecto reflexionaba:

"¿Cómo esperar que de esta clase de célula social puedan salir ciudadanos rectos y nobles? Lógicamente son seres deformados, amaestrados para la mentira y el engaño. Nuestra sociedad, basada en anticuadas normas de predominio absoluto del varón, continua sembrando en la mentalidad masculina el ancestral precepto de su absoluta potestad e irrefrenable libertad de instintos"20

Sumado a lo anterior, los padres no enviaban a los hijos a la escuela,pues los sometían a trabajar desde muy pequeños, y cuando los mandaban era por un año o dos para que aprendieran a leer; situación que se reflejaba en la disminución de estudiantes en los últimos años de la primaria, tanto en las escuelas rurales como en las urbanas.

Por las anteriores razones Ofelia Uribe de Acosta consideraba que en los primeros años se construían los cimientos de hogares responsables y equilibrados tanto por los esposos como por las esposas, lo que facilitaría la apertura de nuevas posibilidades de extensión de la educación popular y el proceso de reeducación de los adultos. De esta manera se instaurarían modos de vida más humanos, que incluyeran nuevos hábitos de higiene, nutrición, primeros auxilios, trabajo y descanso, para así concebir el fundamento de la responsabilidad y el deber, y no el temor y la inhibición que caracterizaba a estos sectores.

En cuanto a la educación secundaria y profesional, Ofelia Uribe de Acosta encuentra que en la Colombia de ese momento existía un totalitarismo disfrazado de democracia, por cuanto el acceso a estos niveles de educación era desigual tanto en las posibilidades como en las oportunidades; situación que terminaba por construir criterios individualistas y exaltaciones de egos en aquellos a quienes se les concedía el privilegio de llegar a ella. Esto llevaba a situaciones desmoralizantes pues, por un lado, fomentaba el arribismo y generaba una desaforada ambición de ganancia, prestigio y poder, que sustituía los ideales humanistas por intereses personalistas y, por otro lado, en la mentalidad de los jóvenes se iba forjando que escalar socialmente no tenía que ver con una formación intelectual, ni con principios respetables, "sino [con] habilidoso malabarismo de 'avivatos' y aduladores profesionales" ${ }^{21}$.

20 Ibídem, 354.

21 Ibídem, 354. 
Lo anterior llevaba a que fuera escaso el grupo de intelectuales rebeldes que buscaran otras formas de pensamiento, cuestión que era necesaria para las transformaciones de la sociedad colombiana. Por esta razón, quienes dirigían el Estado se acomodaban en la difusión homogénea de discursos preconcebidos $\mathrm{y}$ aduladores que anquilosaban cualquier progreso que atentara contra sus intereses. Ofelia Uribe de Acosta pensaba que desconocer la rebeldía era un error de los dirigentes, pues se contribuía a la discriminación y al estancamiento del país, que permanecía encerrado en concepciones arrogantes del pasado; en este sentido invitaba a la clase política para que con valor se corrigieran estos errores, si se aspiraba a que ascendiera la "nómina de intelectuales preparados".

Como resultado de sus recorridos por el país, Ofelia Uribe de Acosta llegó a la conclusión de que se requería un plan educativo para adultos, pues era inocultable que la violencia desatada de arriba hacia abajo se constituía en perversa escuela sobre la mentalidad campesina, pues la niñez que vivió estas atrocidades había crecido, por lo que era necesaria una reorientación y rescate de la población rural del odio; así mismo, para que la clase dirigente pudiese renovar sus ideas y comprendiera que el camino estaba en educar, en vez de perseguir.

\section{Las fallas de la educación colombiana}

Con base en las consideraciones antes mencionadas, Ofelia relacionó a manera de síntesis ocho fallas en la educación colombiana, a saber:

1. Todo lo que tenía que ver con la educación era importado, especialmente de Europa, sin que se tuviese en cuenta a los habitantes de Colombia. Afirmaba: "nuestros sabios viajan al exterior y regresan bañados de luz a elaborar leyes, decretos, disposiciones mil para educarnos y civilizarnos" ${ }^{22}$.

2. A la fecha, 1963, quienes habían ocupado el Ministerio de Educación no tenían nada que ver con la educación y la pedagogía; en general, habían sido abogados y médicos, situación que se reproducía en las secretarías de educación de los departamentos.

3. La situación laboral carecía de estímulos para quienes elegían como profesión el magisterio; por un lado, se demeritaba la profesión y, por otro, aislaba a quienes tenían interés en ella, pues era una carrera que no tenía porvenir; inclusive cuando se aludía al maestro de escuela se hacía de manera despectiva.

22 Ibídem, 354. 
4. Si bien la educación pública se había convertido en un privilegio para las clases adineradas, no garantizaba una formación integral que forjara sujetos activos pertenecientes a una comunidad y a un territorio, en consonancia con la nación en la cual vivían. Señalaba Ofelia Uribe que, dentro de los parlamentarios que eran profesionales, no se encontraba uno solo que orientara acciones hacia el bien común. "No conozco programas concretos de ninguno de ellos porque todos se integran o desintegran momentáneamente alrededor de intereses puramente personalistas [...] Todo lo cual es protuberante demostración de carencia de contenido ideológico, y exteriorización patente de la ausencia de una educación modeladora de ciudadanos" ${ }^{\prime 23}$.

5. Pensaba que la educación que el Estado colombiano proporcionaba a cuentagotas era mezquina, que se quedaba en el discurso. La educación campesina, que debería ser la primera, era la más descuidada; no había acceso a la secundaria, generalmente se reducía a dos años en los que se obtenían conocimientos básicos, y las nociones de ciudadanía que se recibían eran las que inoculaban de manera sectaria los politiqueros en vísperas de elecciones.

6. Ofelia Uribe de Acosta afirmó: “Tengo la sensación de que el Ministerio de Educación, además de falto de técnica pedagógica, es una figura decorativa y juguete de las múltiples fuerzas desvertebradas e incoherentes que protagonizan la farándula educacional" ${ }^{24}$.Consideró, entonces, que en el Ministerio había un desorden administrativo que se caracterizaba por su inercia, que se manifestaba en un escandaloso despilfarro del presupuesto destinado para la educación;cuestión que se comprobaba con el alto número de analfabetismo y con la proliferación de lo que ella llamaba "la vagancia infantil", pues no era más que la reproducción de la educación que se les había proporcionado a los padres. De otro lado, era evidente la formación recibida por la dirigencia colombiana, pues se expresaba en el despilfarro del erario.

7. La descentralización y la autonomía que se les otorgaron a los departamentos a comienzos de la década de los sesenta del siglo XX carecían de planificación y unidad, más aún cuando los departamentos estaban divididos en los que tenían recursos y, por lo tanto, posibilidades educativas y los que no, que se veían obligados a pagar sueldos míseros a los educadores, con las consecuencias que estas condiciones traían, de 
tal manera que lo que se materializaba era una manifiesta discriminación entre la población colombiana.

8. Finalmente, señaló la injerencia e impertinencia de la politiquería, que frustraba los desarrollos y continuidades educativas debido a los traslados y los cambios de maestros y maestras sin justificación alguna, pues no se valoraba al magisterio como formador de la sociedad colombiana, sino como un grupo de empleados menesterosos que se podían cambiar, reemplazar y sacar al antojo de los politiqueros.

\section{CONCLUSIÓN}

\section{HOY COMO AYER}

Indudablemente, la educación colombiana, desde la década de los sesenta a la fecha, ha ido ampliando en términos de cobertura el acceso a la básica primaria, a la secundaria y, en menor medida, a la educación superior. A la par de que se ha expandido el ingreso a la educación, los diferentes gobiernos, en ausencia de políticas públicas estatales, asumen modelos externos con reformas que les son funcionales mas no adecuadas para el país. Es así como en los años setenta hay una adecuación al modelo económico que subsume la academia a la industria, donde ésta lleva a su escenario a la primera, generando el modelo consumista. En los ochenta hay un giro del capitalismo que posiciona la ciencia y la tecnología, convirtiendo al conocimiento en pilar de la economía capitalista, razón por la cual la educación se convierte en un negocio.

La Constitución Política de 1991 cambia el perfil del país, plantea que Colombia es un Estado Social de Derecho y hace un reconocimiento de la diversidad de la población, construyendo en el discurso "un modelo liberal garantista"; paralelamente, hace ajustes neoliberales, en donde la calidad se traslada de los bienes materiales a los procesos educativos: procesos de acreditación y adopción de normas ISSO, entre otros.

Debe anotarse que hoy, como ayer, una de las fallas anotadas por Ofelia Uribe sigue vigente: durante el siglo XX y lo que va corrido del XXI, el Ministerio de Educación no ha estado dirigido por personas formadas en asuntos de la educación, sino que se favorece a quienes técnicamente garanticen la adopción de los nuevos modelos. A propósito de esto vale la pena mencionar la formación de las tres últimas ministras en economía, ingeniería industrial y derecho respectivamente. 
A partir de los años sesenta, Colombia intensificó su transición demográfica de sociedad rural a sociedad urbana, impulsada por el proceso de industrialización y su correlativa violencia; hoy el $70 \%$ de la población colombiana habita en las ciudades. La educación en el ámbito rural excluye de la básica primaria a un número significativo del campesinado, principalmente por las condiciones de pobreza, y la mayoría de quienes acceden logran como máximo finalizarla. "Se conoció por cifras del DANE que la deserción escolar disminuyó 0,4\% entre 2011 y 2012". El estudio precisa que se pasó de 10.641.243 matriculados en 2012 a 10.540.711 en 2013 y que "para preescolar y básica primaria la caída fue de 1,3\% y para la básica secundaria y media el descenso fue del 0,5\%." 25

Concluir la secundaria y acceder a la educación superior no les garantiza a los jóvenes mejores condiciones como se evidencia en la alta deserción de la educación superior. En diciembre de 2013, según datos del Ministerio de Educación Nacional, aproximadamente 2.000.000 jóvenes estaban matriculados en las universidades, sin que ello garantizara una movilidad social que les permitiera mejores condiciones de vida; es más, en este nivel educativo también existe una alta deserción por la misma causa: la pobreza. El mismo Ministerio había establecido en el 2009 que las tasas de deserción en el educación superior se encontraban "entre el 45\% y el 50\%, lo que significaría que cerca de uno de cada dos estudiantes que ingresan al sistema no culminaría sus estudios" ${ }^{26}$.

De otro lado, el sistema nacional educativo no permite un paso integral y armónico entre los distintos niveles educativos. La básica primaria y la secundaria están legisladas en la llamada Ley General de Educación —Ley 115 de 1984-, que excluye a la educación superior; esta se legisló ocho años más tarde en la Ley 30 de 1992. Esto muestra que se hace urgente un sistema que articule todo el proceso educativo, pues lo que realmente incide en la problemática de la educación en Colombia, como ya lo afirmaba Ofelia Uribe de Acosta desde los años sesenta, es la pobreza y la desigualdad.

La condición del magisterio, abordada por la autora de Una Voz Insurgente, continúa siendo subvalorada, lo que se evidencia no solo en la condición socioeconómica de esta profesión, sino en que ser maestro hoy se constituye en un refugio de segunda línea para cualquier profesional desempleado. Así se establece en el Decreto 1278 de 2002 —Estatuto de Profesionalización Docente-, en el que se plantea que cualquier profesional puede ejercer como profesor o profesora si cursa un programa de pedagogía de un año en una institución de educación superior.

25 El Espectador, http://www.elespectador.com/noticias/educacion/preocupantes-cifras-de-desercion-escolar-articulo-518837 (25/9/2014).

26 Ministerio de Educación Nacional (2014). http://www.mineducacion.gov.co/sistemasdeinformacion/1735/articles254702_libro_ desercion.pdf pág. $67,(4 / 10 / 2014)$. 
Actualmente en Colombia el debate se centra en los diálogos de paz, en donde el asunto de la educación debe ser nodal, y no puede estar solamente en el ámbito de la comunidad educativa: estudiantes, maestros y maestras, colegios y universidades, sino es un tema que atañe a la sociedad en su conjunto. Tal como lo señaló en su momento Ofelia Uribe de Acosta, la arquitectura de un pueblo se edifica sobre la justicia, la educación, la salud y la economía, cuestión que ha de articularse con la formación ética y moral de ciudadanía.

Finalmente, el llamado a la cultura política hecho por Ofelia Uribe de Acosta se constituye en fundamental para la transformación de la sociedad colombiana, con el fin de que se impida el desconocimiento del inconformismo y de la rebeldía y se posibilite una restauración del odio tan acendrado en nuestro país. Como señalan estudiosos del tema, la injusticia y la violencia son algunas de las causas de la aparición de movimientos insurgentes, producto de los privilegios e intereses arrogados por las élites, que siguen considerando que el talento para gobernar es heredado, sin entender la necesidad de la cultura política en unos y otros, pues no se puede desconocer que parte de la dirigencia colombiana y muchos sectores pobres han sido permeados por perversas estructuras como el narcotráfico y el paramilitarismo, con sus nefastas consecuencias.

Las dos últimos fallas señaladas por Ofelia —el despilfarro del erario, la no planificación y la división entre regiones ricas y pobres— tienen dos elementos: uno, la politiquería, que sigue siendo devastadora y de la que hablaba Ofelia Uribe de Acosta, politiquería que luego fue llamada corrupción y clientelismo y a la que hoy, eufemísticamente, se le dice mermelada; cuestión que se evidencia con la Ley de Regalías, que privilegia proyectos productivos relacionados con la ampliación de los mercados por sectores minoritarios, que dejan rezagadas las propuestas educativas; asimismo, los programas asistenciales, como Familias en Acción o el Proyecto Red-Unidos, se han convertido en instrumento de campañas políticas. El otro elemento es que se sigue ignorando la diversidad social, connatural a la nación colombiana, y con ello los múltiples saberes de nuestras comunidades nativas, afrodescendientes y otras minorías que conforman el arco iris de habitantes de Colombia; así se haya reconocido la diversidad étnica y cultural en la Constitución Política de 1991, se sigue ignorando y agrediendo por medio del desplazamiento forzado y la violencia sistemática, que son producto de la injerencia de proyectos de las multinacionales, con los cuales cohonestan de manera abierta quienes manejan el Estado colombiano. 


\section{FUENTES}

Acosta de Uribe, Ofelia. Una Voz Insurgente. Bogotá: Editorial Guadalupe, 1963.

Asociación Colombiana para el Estudio de la Población - ACEP — . La población de Colombia. COMMITER, 1974. http:/ / www.cicred.org/Eng/Publications/pdf/ c-c9.pdf. 19/06/2014.Contravía Programa de la televisión colombiana, capitulo 53, emitido el 26/08/2004.

El Espectador, http://www.elespectador.com/noticias/educacion/preocupantescifras-de-desercion-escolar-articulo-518837.

Ministerio de Educación Nacional,http://www.mineducacion.gov.co/ sistemasdeinformacion/ 1735 /articles254702_libro_desercion.pdf pág. 67, $(4 / 10 / 2014)$

Torres, Anabel. “Una Voz Insurgente. Entrevista con Ofelia Uribe de Acosta”, Revista Voces Insurgentes. Universidad Central, 1986.

Velásquez Toro, Magdala. Ofelia Uribe de Acosta (Credencial Historia No.68) http: / / www.banrepcultural.org / blaavirtual / revistas / credencial / agosto95 / agosto4.htm(10/04/2014).

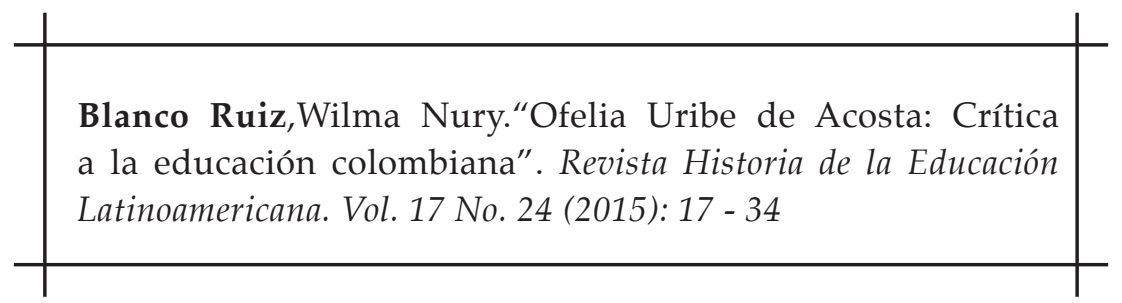

